
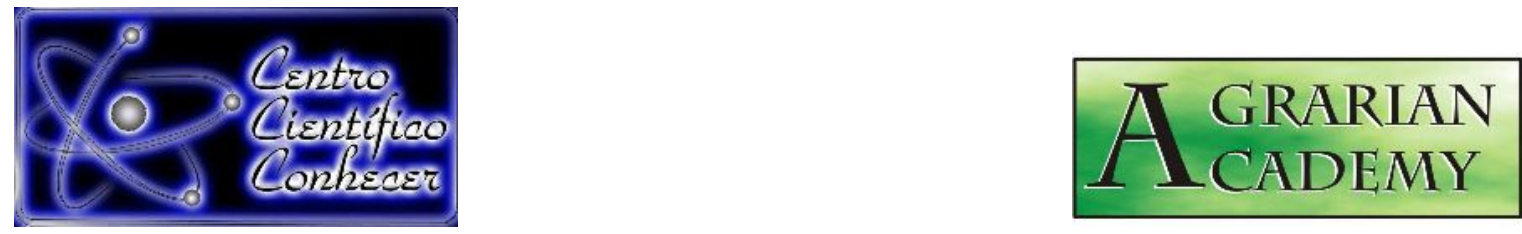

\title{
GERMINAÇÃO DE SEMENTES DE CAPIM AMARGOSO (DIGITARIA INSULARIS) NA PRESENÇA DE HERBICIDAS RESIDUAIS
}

Gilmarcos de Carvalho Corrêa ${ }^{1}$, Marivone Moreira dos Santos ${ }^{1}$, Luís Carlos Cunha Júnior $^{1}$, Fernanda Rodrigues dos Santos ${ }^{2}$, Rodrigo Andrade Leitão ${ }^{2}$

${ }^{1}$ Professor(a) Doutor(a) da Escola de Agronomia da Universidade Federal de Goiás - UFG, Goiânia-GO, Brasil (gilmarcoscorrea@gmail.com).

${ }^{2}$ Graduando(a) do Curso de Agronomia da Escola de Agronomia da Universidade Federal de Goiás, Goiânia-GO, Brasil.

Recebido em: 02/06/2019 - Aprovado em: 15/06/2019 - Publicado em: 22/07/2019 DOI: 10.18677/Agrarian_Academy_2019a17

\begin{abstract}
O manejo de capim amargoso (Digitaria insularis L. Fedde) em áreas agrícolas do Brasil tem se mostrado, ultimamente, um desafio difícil para produtores e técnicos. Devido à competitividade desta planta daninha, o que dificulta seu controle em áreas de plantio direto, torna-se interessante a busca de informações sobre a eficiência de herbicidas que poderiam suprimir o banco de sementes do solo, dispersão de sementes viáveis e reinfestação das áreas manejadas. O objetivo deste trabalho foi avaliar o efeito de herbicidas residuais sobre os percentuais de sementes não germinadas, plântulas mortas e plântulas vivas de capim amargoso. Os herbicidas foram diluídos e aplicados em Gerbox $^{\circledR}$ com papel mata borrão contendo as sementes e as avaliações foram feitas aos 7, 14 e 21 dias após aplicação. Os herbicidas testados foram atrazina, diclosulam, flumioxazina, s-metolacloro e sulfentrazona. O herbicida sulfentrazona aumentou a incidência de sementes não germinadas. Diclosulam e flumioxazina reduziram o número de plântulas vivas de Digitaria insularis.
\end{abstract}

PALAVRAS-CHAVE: Controle químico, plantas daninhas perenes, plantas invasoras.

\section{GERMINATION OF SOURGRASS (DIGITARIA INSULARIS) SEEDS IN PRESENCE OF RESIDUAL HERBICIDES}

\begin{abstract}
The management of sourgrass (Digitaria insularis L. Fedde) in Brazil's agricultural areas has showed a hard challenge for growers and technicians in last years. Due competitiveness of this weed becoming difficult the control in no-tillage areas, it's interesting information search about herbicides efficiency. Herbicides could suppress soil seed bank, viable seed dispersion and maneged areas reinfestation. The aiming of study was to evaluate effect of residual herbicides in percentage of no germinated
\end{abstract} AGRARIAN ACADEMY, Centro Científico Conhecer - Goiânia, v.6, n.11; p. 175 2019 
seeds, dead plantets and living plantets of sourgrass. Herbicides were diluted and applied in Gerbox ${ }^{\circledR}$ with absorbent paper containing seeds. The assessments were performed 7, 14 and 21 days after application. Tested herbicides were atrazine, diclosulam, flumioxazine, s-metolachlor and sulfentrazone. The sulfentrazone herbicide increased no germinated seeds incidence. Diclosulam and flumioxazine reduced living plantets number of Digitaria insularis.

KEYWORDS: Chemical control, perennial weeds, weeds.

\section{INTRODUÇÃO}

O potencial produtivo das culturas agrícolas depende, dentre outros fatores, da época e intensidade de infestação de plantas daninhas, sendo necessário seu controle, uma vez que as plantas invasoras competem com a cultura por fatores essenciais para seu desenvolvimento como luz, água e nutrientes. Além da competição, as plantas daninhas abrigam insetos, patógenos e nematoides, além de dificultar a colheita e reduzir a qualidade do produto colhido (CONCENÇO et al., 2014; ANDREANI JR. et al., 2018; GUIMARÃES et al., 2019).

Dentre as diversas espécies de plantas daninhas, tanto monocotiledôneas quanto eudicotiledôneas, que infestam as lavouras de grãos, algumas têm se destacado pela sua grande plasticidade ecológica, o que amplia sua esfera de infestação, pela velocidade e hábito de crescimento, pela dificuldade de controle químico e adaptação ao sistema de plantio direto, que corresponde a cerca de metade da área cultivada com grãos no Brasil e, ainda, mais predominante na Região Centro Oeste e Estado de Goiás (ZOBIOLE et al., 2018; GUIMARÃES et al., 2019).

Com a expansão das áreas de cultivo, principalmente, de soja, milho e algodão resistentes a glifosato, no sistema de plantio direto, diversas plantas daninhas se adaptaram ao ambiente mais estável, sem revolvimento de solo, e, principalmente, ao manejo realizado com herbicidas aplicados em pós emergência, normalmente em associação com o herbicida glifosato, produtos esses que se caracterizam por apresentar ausência ou baixo efeito residual sobre as plantas daninhas, após sua aplicação (MELO et al., 2017; PEREIRA et al., 2018).

A utilização constante de herbicidas, sem efeito residual longo, levou à seleção, nas áreas de plantio direto, de plantas daninhas com baixa absorção foliar de herbicidas ou que apresentem reprodução complexa, através de sementes e propágulos vegetativos, tais como rizomas e tubérculos. Plantas daninhas como Conyza spp. (buvas), Chloris elata (capim branco) e Digitaria spp. (capins colchão) e, destacadamente, Digitaria insularis (capim amargoso) vêm ampliando, tanto sua área, quanto seus níveis de infestação (TROPALDI et al., 2017; CORREIA; RESENDE, 2018; ZOBIOLE et al., 2018).

O Gênero Digitaria com cerca de 300 espécies de plantas, reúne diversas espécies de grande importância em termos de infestação de áreas produtoras de grãos no Brasil, que reúne a maior diversidade de espécies desse Gênero na América, destacando-se o capim amargoso (Digitaria insularis) por seu alto potencial de infestação e dificuldade de controle (GAZOLA et al., 2016; TROPALDI et al., 2017).

Digitaria insularis apresenta elevada produção de sementes envolvidas em densa pilosidade, com elevado poder germinativo, podendo ser disseminadas a longas distâncias pelo vento, praticamente, o ano todo. Trata-se de planta daninha 
com desenvolvimento rápido e agressivo, que se desenvolve bem em solos distróficos, reproduzindo-se por sementes e por rizomas e formando touceiras de bom tamanho a partir dessas estruturas reprodutivas (LORENZI, 2008; MELO et al., 2015).

O nível de infestação de Digitaria insularis tem aumentado naquelas áreas de produção onde não se adotam culturas de cobertura como prática de manejo durante a entressafra, tornando-se uma das principais plantas daninhas no Brasil em áreas de produção de grãos, principalmente em regiões com intenso cultivo de culturas transgênicas, resistentes a glifosato (PETTER et al., 2015).

A intensa utilização dessas culturas geneticamente modificadas, resistentes ao glifosato, tornou este produto, pós emergente e de amplo espectro de controle, o principal herbicida utilizado no manejo de plantas daninhas nessas culturas, tendose por conta dessa intensa e constante utilização, o desenvolvimento de plantas daninhas resistentes ao glifosato (MELO et al., 2019; NETTO et al., 2015).

O desenvolvimento de resistência a um produto ocorre quando a contínua utilização de um herbicida resulta em prolongado período de convivência, entre plantas daninhas e herbicida, e forte pressão de seleção, que leva ao aumento de frequência de biótipos de plantas invasoras resistentes ao herbicida, biótipos estes que já ocorrem naturalmente na área, mas em baixíssimas frequências, nas populações de plantas daninhas (CHRISTOFFOLETI et al., 2014).

Pelas características de agressividade e competitividade de Digitaria insularis, não se deve, como mostra a situação atual, basear-se seu controle em um único herbicida, ainda que o glifosato fosse o produto mais usado nas várias fases fenológicas do capim amargoso, ainda que com grande perda de eficiência, a partir de 45 dias de emergência, pela formação de rizomas nas plantas de capim amargoso, conforme relatado por GAZOLA et al. (2016).

Ainda dentro da linha de herbicidas pós emergentes, buscaram-se misturas heterólogas de produtos associados ao glifosato, principalmente herbicidas inibidores de ACCase, que complementassem seu efeito sobre Digitaria insularis. Zobiole et al. (2016) e Guimarães et al. (2019) testaram misturas de glifosato com os graminicidas cletodim e haloxifope-p-metil, com níveis de controle de médio a baixo; os primeiros autores relataram necessidade de aplicação sequencial de glifosato e graminicidas, enquanto os segundos autores recomendaram associação da aplicação das misturas ao uso de roçadeira.

Licorini et al., (2015) em estudo no Paraná, relataram resistência de biótipos de Digitaria insularis a glifosato, associada à tolerância ao graminicida cletodim. Pereira et al., (2018) reportaram níveis de controle de capim amargoso abaixo de $70 \%$, com utilização de misturas de glifosato com o graminicida haloxifope e auxinas sintéticas dicamba, 2,4-D e halauxifena. O baixo nível de sucesso no controle pode ser atribuído ao padrão fenológico do capim amargoso que reúne em uma mesma população plantas oriundas de sementes, plantas oriundas de rizomas e plantas que florescem, praticamente, o ano todo (GAZOLA et al., 2016).

O controle eficaz de Digitaria insularis parece demandar um manejo mais diversificado, baseado em um leque mais amplo de herbicidas que possam controlar essa planta daninha em suas diversas fases fenológicas, inclusive após a emissão de rizomas e entrada em florescimento (ZOBIOLE et al., 2016). Neste sentido, diversos autores como Drehmer et al., (2015), Tropaldi et al., (2017), Melo et al., (2017) e Andrade Jr. et al., (2018) destacaram o potencial dos herbicidas residuais, usados na dessecação pré-plantio das culturas, no controle de capim amargoso. 
O objetivo deste trabalho foi avaliar-se o efeito dos herbicidas atrazina, diclosulam, flumioxazina, s-metolacloro e sulfentrazona sobre a geminação de sementes de Digitaria insularis em condições de laboratório.

\section{MATERIAL E MÉTODOS}

O experimento foi conduzido no Laboratório de Análise de Sementes da Escola de Agronomia da Universidade Federal de Goiás, Goiânia-GO, de janeiro a maio de 2018. As sementes de capim amargoso (Digitaria insularis) foram coletadas na Fazenda Nossa Senhora Aparecida, localizada no Município de Edéia-GO, nas coordenadas geográficas Latitude 17을 20,5' 95" Sul e Longitude 49 58,18' 69" Oeste.

O clima é Tropical, classificado como Aw de Köppen e Geiger, segundo Cardoso et al. (2014), com temperatura média anual de $24,1^{\circ} \mathrm{C}$ e pluviosidade média anual de $1.423 \mathrm{~mm}$. A área de coleta das sementes apresenta histórico de cultivo de soja e milho há mais de vinte anos (Tabela 1).

Tabela 1. Características físico-químicas do Latossolo Vermelho da área de coleta de sementes para estudo do efeito inicial de herbicidas com controle residual sobre a germinação de sementes de capim amargoso (Digitaria insularis). Edéia-GO. 2018.

\begin{tabular}{|c|c|c|c|c|c|c|c|c|c|}
\hline & & & CAR & ACTE & ZIST & CAS FISIC & -QUI'MI & & \\
\hline $\begin{array}{c}\mathrm{pH} \\
\left(\mathrm{CaCl}_{2}\right)\end{array}$ & $\mathrm{Al}^{3-}$ & $\begin{array}{r}\mathrm{Ca}^{2+} \\
(\mathrm{C}\end{array}$ & $\begin{array}{l}\mathrm{Mg}^{2} \\
\mathrm{~mol} / \mathrm{d}\end{array}$ & $\begin{array}{l}\mathrm{K}^{+} \\
\left.\mathrm{m}^{3}\right) \\
\end{array}$ & & $\begin{array}{c}\mathrm{P} \\
\left(\mathrm{mg} / \mathrm{dm}^{3}\right)\end{array}$ & $\begin{array}{r}\text { M.O. } \\
(\mathrm{g} / \mathrm{Kg})\end{array}$ & $\begin{array}{l}\text { S.B. } \\
(\%)\end{array}$ & \begin{tabular}{|c|}
$\begin{array}{c}\text { Arg. Areia Silte } \\
(\%)\end{array}$ \\
\end{tabular} \\
\hline 5,3 & 0,0 & 2,5 & 0,9 & 0,11 & 6,9 & 21,7 & 19,0 & 51,0 & \begin{tabular}{|l|l|l|}
42,5 & 52,5 & 5,0 \\
\end{tabular} \\
\hline
\end{tabular}

M.O.= matéria orgânica; S.B.= saturação de bases; Arg.= argila.

A coleta do material foi realizada introduzindo-se as panículas dentro de sacos de papel pardo e, com agitação, forçou-se o desprendimento dos rácemos, somente, das sementes já com plena maturação fisiológica, aptas a compor as parcelas nos contentores.

Os contentores Gerbox ${ }^{\circledR}$ foram lavados em água corrente com sabão e, em seguida, foi feita sua assepsia com álcool a $70 \%$, cerca de 48 horas antes da montagem das parcelas. As sementes foram tratadas com fungicida de contato / sistêmico (Maxin XL), contendo $10 \mathrm{~g} \cdot \mathrm{L}^{-1}$ de Metalaxil-m e $25 \mathrm{~g} \cdot \mathrm{L}^{-1}$ de Fludioxonil, à dose de $200 \mathrm{~mL}$ para $100 \mathrm{Kg}$ de sementes, conforme a recomendação para gramíneas. Foram colocadas 100 sementes por Gerbox ${ }^{\circledR}$.

Em cada Gerbox ${ }^{\circledR}$ foi colocada uma folha de papel mata borrão $(10 \times 10 \mathrm{~cm})$ e, antes da deposição das sementes no papel, este foi umedecido com $5 \mathrm{~mL}$ de água (testemunha) ou $5 \mathrm{~mL}$ da calda de aplicação composta por água e herbicida. Os herbicidas testados, suas classificações por mecanismo de ação, segundo Rodrigues e Almeida (2018), e dosagem por Gerbox ${ }^{\circledR}$ encontram-se na Tabela 2.

As parcelas montadas foram colocadas em Germinador com controle de temperatura, simulando temperatura diurna de $35^{\circ} \mathrm{C}$ e temperatura noturna de $25^{\circ}$ C, com 12 horas de luz, segundo as Regras para Análise de Sementes do Ministério da Agricultura, Pecuária e Abastecimento, usando-se protocolo para Panicum spp., pela falta de protocolo para Digitaria spp. (BRASIL, 2017). 
Tabela 2. Produtos utilizados no estudo do efeito inicial de herbicidas com controle residual sobre a germinação de sementes de capim amargoso (Digitaria insularis).

\begin{tabular}{llcc}
\hline HERBICIDAS & CLASSIFICAÇÃO & DOSES g i.a.ha & DOSES $^{-1}$ GERBOX \\
\hline atrazina & Inibidor FSII & $1.500,00$ & $1,5.10^{-3}$ \\
\hline diclosulam & Inibidor de ALS & 35,28 & $3,5.10^{-5}$ \\
\hline flumioxazina & Inibidor de Protox & 50,00 & $5,0.10^{-5}$ \\
\hline s-metolacloro & Inib. Divisão Celular & $1.440,00$ & $1,4.10^{-3}$ \\
\hline sulfentrazone & Inibidor de Protox & 250,00 & $2,5.10^{-4}$ \\
\hline
\end{tabular}

As avaliações foram feitas aos 7, 14 e 21 dias após a aplicação, realizando-se a contagem de sementes não germinadas, plântulas mortas e plântulas vivas. Os tratamentos foram testemunha e cinco herbicidas e cada tratamento era constituído por parcelas de 400 sementes com 4 repetições, totalizando 1.600 sementes por tratamento.

Utilizou-se o Delineamento Inteiramente Casualizado e os dados foram submetidos à análise de variância com teste de Tukey a $5 \%$ de probabilidade. Os dados foram transformados para raiz quadrada de $(Y+1)$ onde $Y$ corresponde aos dados originais, conforme Zimmermann (2004). Para as análises estatísticas utilizouse o programa estatístico Assistat ${ }^{\circledR} 7.7$ (SILVA; AZEVEDO, 2016).

\section{RESULTADOS E DISCUSSÃO}

As porcentagens médias obtidas no experimento para as variáveis sementes não germinadas (NG), plântulas mortas (PM) e plântulas vivas (PV) estão apresentadas na Tabela 3.

Tabela 3. Efeito de herbicidas residuais, sobre a germinação de sementes de Digitaria insularis, para as variáveis sementes não germinadas (NG), plântulas mortas (PM) e plântulas vivas (PV) aos 21 dias após aplicação. Goiânia-GO. 2018.

\begin{tabular}{lcccccc}
\hline \multicolumn{7}{c}{ VARIÁVEIS } \\
\hline \multirow{2}{*}{ TRATAMENTOS } & \multicolumn{3}{c}{ NG } & \multicolumn{2}{c}{ PM } & \multicolumn{2}{c}{ PV } \\
\cline { 2 - 7 } & Transf. & Orig.(\%) & Transf. & Orig.(\%) & Transf. & Orig.(\%) \\
\hline T0 (testemunha) & $4,37 \mathrm{bc}$ & 19,00 & $8,74 \mathrm{a}$ & 75,56 & $2,16 \mathrm{ab}$ & 5,44 \\
\hline T1 (atrazina) & $4,32 \mathrm{bc}$ & 18,00 & $8,75 \mathrm{a}$ & 75,62 & $2,52 \mathrm{a}$ & 6,38 \\
\hline T2 (s-metolacloro) & $4,98 \mathrm{~b}$ & 24,50 & $8,60 \mathrm{a}$ & 73,43 & $1,50 \mathrm{ab}$ & 2,07 \\
\hline T3 (diclosulam) & $3,90 \mathrm{c}$ & 15,60 & $9,22 \mathrm{a}$ & 84,18 & $1,06 \mathrm{~b}$ & 0,26 \\
\hline T4 (flumioxazina) & $5,28 \mathrm{ab}$ & 27,60 & $8,53 \mathrm{a}$ & 72,06 & $1,12 \mathrm{~b}$ & 0,34 \\
\hline T5 (sulfentrazona) & $6,11 \mathrm{a}$ & 37,70 & $7,46 \mathrm{~b}$ & 57,50 & $1,55 \mathrm{ab}$ & 4,80 \\
\hline
\end{tabular}

Transf.: dados transformados; Orig.: dados originais; Médias seguidas de mesma letra, na coluna, não diferem entre si, pelo teste de Tukey a $5 \%$ de probabilidade.

Observa-se na Tabela 3 que para a variável sementes não germinadas (NG) de Digitaria insularis, aos 21 d.a.a., apenas o herbicida sulfentrazona (T5) diferiu da testemunha, apresentando aumento do número de sementes não germinadas da planta daninha.

Os índices de sementes não germinadas entre 15,6 e $37,7 \%$, observados para os tratamentos com diclosulam e sulfentrazona, respectivamente, mostraram-se bastante baixos, se comparados com os resultados obtidos por Mendonça et al. (2014) que registraram 67 a $84 \%$ de sementes não germinadas, à temperatura de $25^{\circ} \mathrm{C}$ e com luz intermitente, ou seja, condições semelhantes às adotadas neste 
trabalho e consideradas por aqueles autores bastante próximas às condições ideais para a espécie.

Mendonça et al. (2014), também, reportaram variação de cinética de germinação para sementes de Digitaria insularis de procedências geográficas distintas, com genótipos adaptados a cada situação in situ como resposta à pressão de seleção exercida por cada ambiente. O presente trabalho foi conduzido com sementes de uma única procedência o que poderia determinar seu padrão de germinação, uma vez que certos genótipos seriam, intrinsecamente, mais vigorosos que outros, característica que poderia ser acentuada pelo regime de luz intermitente com 12 horas de claro e 12 horas de escuro, conforme reportado por Gazola et al. (2016).

Observa-se na Tabela 3 que para a variável plântulas mortas (PM) de capim amargoso, aos 21 d.a.a., apenas o herbicida sulfentrazona (T5) diferiu da testemunha (T0), apresentando as menores médias de plântulas mortas da espécie invasora. Os herbicidas diclosulam e atrazina apresentaram as maiores médias de plântulas mortas, acima de $75 \%$, porém sem diferença da testemunha.

O desenvolvimento inicial de genótipos de capim amargoso seria influenciado pelas características de seu sítio de origem e pelo tipo de planta que deu origem às sementes (GAZOLA et al., 2016). Para os autores, sementes oriundas de plantas originárias de rizomas apresentariam características morfológicas diferenciadas, que dificultariam seu controle, e vigor inicial superior em relação a plantas originadas de sementes.

Mendonça et al. (2014) relataram que a germinação de sementes de capim amargoso só cessou aos 75 dias após a semeadura para materiais de quatro procedências e que seu comportamento em relação à luz, colocaria as sementes dessa espécie dentro do grupo das fotoblásticas positivas. O vigor das plântulas, ao longo do período de germinação não pareceu ser determinado pela velocidade de germinação.

As condições ideais para germinação e, portanto, para o desenvolvimento inicial das plântulas, seriam a ocorrência de temperaturas na faixa de $35^{\circ} \mathrm{C}$ e presença de luz intermitente, além de boa disponibilidade de água, o que favoreceria o processo de embebição e atividade enzimática das sementes, eliminando barreiras à germinação como tegumento impermeável (MENDONÇA et al., 2014). No presente trabalho adotaram-se temperaturas diurna de $25^{\circ} \mathrm{C}$ e noturna de $35^{\circ} \mathrm{C}$, com regime de luz intermitente de 12 horas; estas condições poderiam estimular a germinação de genótipos menos vigorosos que responderiam ao forte estímulo ambiental para quebra de dormência, porém com pouco vigor para seu estabelecimento.

O forte estímulo para quebra de dormência das sementes de Digitaria insularis poderia ser, ainda, intensificado pela simples deposição das sementes sobre o papel mata borrão, com grande disponibilidade de água, oxigênio e luz, sem os impedimentos representados pelo enterrio das sementes e presença de coberturas de solo (PETTER et al., 2015; MARTINS et al., 2017). Este fato poderia representar uma situação excepcionalmente favorável à germinação, uma vez que para Pereira et al. (2017) a grande capacidade reprodutiva e de infestação seria inerente a espécies de grande agressividade e plasticidade ecológica como capim amargoso.

Observa-se na Tabela 3 que para a variável plântulas vivas (PV) de capim amargoso, aos 21 d.a.a., os resultados mostraram porcentagens médias de sobrevivência de plântulas de 0,26 a 6,38\%, com o herbicida atrazina (T1) 
apresentando a média de sobrevivência de plântulas mais elevada, ainda que não diferindo da testemunha (T0) não tratada com herbicida.

Os herbicidas diclosulam (T3) e flumioxazina (T4) diferiram da testemunha (T0), reduzindo a incidência de plântulas vivas de Digitaria insularis a valores médios de 0,26 e 0,34\%, respectivamente, enquanto a testemunha apresentou média de sobrevivência de plântulas de 5,44\% (Tabela 3).

Melo et al. (2017) testaram os herbicidas atrazina, s-metolacloro e flumioxazina, aplicados em pré emergência, para controle inicial de Digitaria insularis, antes que as plantas daninhas atingissem sua fase fenológica de mais difícil controle. Os resultados mostraram uma taxa de sobrevivência de plântulas, aos 20 d.a.a., de 0 a $9 \%$. As doses de herbicidas utilizadas pelos autores foram semelhantes às doses usadas neste trabalho, representando as doses mais usadas a campo, com exceção de atrazina que foi usada à dose de $2.500 \mathrm{~g}$ i.a.ha ${ }^{-1}$ e no presente trabalho à dose de $1.500 \mathrm{~g}$ i.a.ha ${ }^{-1}$.

Pereira et al. (2017) estudaram o desenvolvimento inicial de diferentes biótipos de capim amargoso, resistente e suscetível a glifosato, e relataram diferenças no padrão de acúmulo de matéria seca nas raízes e parte aérea de plântulas. O maior acúmulo de reservas no sistema radicular predisporia as plantas a apresentar maior resistência a condições adversas, inclusive ao efeito de herbicidas residuais.

Andreani Jr. et al. (2018) estudaram o efeito de extratos vegetais aquosos sobre a germinação de Digitaria insularis e relataram atraso na emissão de plântulas desta espécie, quando as sementes foram tratadas com extrato de Eucaliptus camaldulensis.

Petter et al. (2015) investigaram a influência de diferentes níveis de palhada de várias culturas de cobertura do solo sobre as características de germinação de sementes e desenvolvimento inicial de plantas de capim amargoso. Os resultados

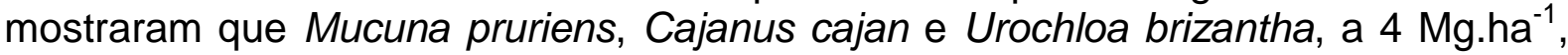
promoveram expressiva redução na emergência de plantas, velocidade de germinação e massa seca e volume radiculares.

A alta suscetibilidade de sementes de capim amargoso à presença de cobertura de solo estaria relacionada, primariamente, ao mecanismo fotoblástico de Digitaria insularis que seria sensível à redução de luz e possível efeito alelopático resultante da decomposição do material de cobertura (PETTER et al., 2015).

Os mesmos autores sugeriram que o manejo de culturas de cobertura incrementaria a eficiência do controle químico precoce de capim amargoso com herbicidas residuais, no que concordariam com Melo et al. (2017) e Andreani Jr. et al. (2018).

\section{CONCLUSÃO}

O herbicida sulfentrazona apresentou aumento de sementes não germinadas (NG) de Digitaria insularis e os herbicidas diclosulam e flumioxazina apresentaram redução de plântulas vivas (PV) da planta daninha.

\section{AGRADECIMENTOS}

Ao Sr. Luiz Mauro de Souza, funcionário da EA-UFG, pelas contribuições e grande dedicação na execução do trabalho de pesquisa. 


\section{REFERÊNCIAS}

ANDRADE JR., E.J.; BARROSO, A.L.L.; MORAES, V.H.; GOMES, F.H.F.; BASTOS, A.V.S.; LOPES FILHO, L.C. Controle residual de capim amargoso na soja cultivada em região de cerrado. Científic@ Multidisciplinary Journal, v. 5, n. 3, p. 48-55. 2018. Disponível em: <http://dx.doi.org/10.29247/2358-260X.2018v5i3.p48-55>. doi: 10.29247/2358-260X.2018v5i3.p48-55

ANDREANI JR., R.; OTERO, M.Q.; SILVA, M.M. Efeito de extratos vegetais aquosos sobre a germinação de plantas daninhas. Enciclopédia Biosfera, v. 15, n. 27, p. 188-194. 2018. Disponível em: <https://dx.doi.org/10.18677/EnciBio_2018A41>. doi: 10.18677/EnciBio_2018A41

CARDOSO, M.R.D.; MARCUZZO, F.F.N.; BARROS, J.R. Classificação climática de Köppen-Geiger para o Estado de Goiás e o Distrito Federal. ACTA Geográfica, v. 8, n. 16, p. 40-55. 2014. Disponível em: <https://dx.doi.org/10.5654/actageo2014.00 04.0016>. doi: 10.5654/actageo2014.0004.0016

CHRISTOFFOLETI, P.J.; NICOLAI, M.; MELO, M.S.C. Resistência de plantas daninhas a herbicidas. In: MONQUERO, P.A. (Org.). Aspectos da biologia e manejo das plantas daninhas. São Carlos: Rima, 2014. p. 257-282.

CONCENÇO, G.; ANDRES, A.; SILVA, A.F.; GALON, L.; FERREIRA, E.A.; ASPIAZÚ, I. Ciência das plantas daninhas: histórico, biologia, ecologia e fisiologia. In: MONQUERO, P.A. (Org.). Aspectos da biologia e manejo das plantas daninhas. São Carlos: Rima, 2014. p. 1-29.

CORREIA, N.M. ; RESENDE, Í. Response of three Chloris elata populations to herbicides sprayed in pre and post-emergence. Planta Daninha, v. 36, e018176117. 2018. Disponível em : <http://dx.doi.org/10.1590/S0100-835820183601 00078 > doi: 10.1590/S0100-83582018360100078

DREHMER, M.H.; ZAGONEL, J.; FERREIRA, C.; SENGER, M. Eficiência de herbicidas aplicados em pré-emergência para o controle de Digitaria insularis na cultura do feijão. Revista Brasileira de Herbicidas, v. 14, n. 2, p. 148-154. 2015. Disponível em: <http://dx.doi.org/10.7824/rbh.v14i2.395>. doi: 10.7824/rbh.v14i2.395

GAZOLA, T.; BELAPART, D.; CASTRO, E.B.; CIPOLA FILHO, M.L.; DIAS, M.F. Características biológicas de Digitaria insularis que conferem sua resistência a herbicidas e opções de manejo. Científic@, v. 44, n. 4, p. 557-567. 2016. Disponível em: <https://dx.doi.org/10.15361/1984-5529.2016v44n4p557-567>. doi:10.15361/198 4-5529.2016v44n4p557-567 
GUIMARÃES, J.L.N.; ARAÚJO, F.C.; SOUSA, G.F.P.; VELOSO, J.C.L.; RABELO, G.L.; FREITAS, M.A.M. Alternativas de controle de capim amargoso. Multi-Science Journal, v. 2, n. 1, p. 57-60. 2019. Disponível em: <https://www.ifgoiano.edu.br/perio dicos/>.

LICORINI, L.R.; GANDOLFO, M.A.; SORACE, M.A.; OSIPE, R.; COSSA, C.A.; OSIPE, J.B. Identificação e controle de biótipos resistentes de Digitaria insularis (L.) Fedde ao glyphosate. Revista Brasileira de Herbicidas, v. 14, n. 3, p. 141-147. 2015. Disponível em:<http://dx.doi.org/10.7824/rbh.v14i3.394>. doi: 10.7824/rbh.v14i 3.394

LORENZI, H. Plantas daninhas do Brasil: terrestres, aquáticas, parasitas e tóxicas. 4. ed. Nova Odessa-SP: Instituto Plantarum, 2008. 640 p.

MARTINS, J.F.; BARROSO, A.A.M.; ALVES, P.L.C.A. Effects of environmental factors on seed germination and emergence of glyphosate resistant and susceptible sourgrass. Planta Daninha, v. 35, e017164499. 2017. Disponível em : <http://dx.doi.org/10.1590/S0100-8358201735010039>. doi: 10.1590/S0100-835820 1735010039

MELO, M.S.C.; ROCHA, L.J.F.N.; BRUNHARO, C.A.C.G.; NICOLAI, M.; TORNISIELLO, V.L.; NISSEN, S.J.; CHRISTOFFOLETI, P.J. Sourgrass resistance mechanism to the herbicide glyphosate. Planta Daninha, v. 37, e019185746. 2019. Disponível em: <http://dx.doi.org/10.1590/S0100-83582019370100033>. doi: 10.159 0/S0100-83582019370100033

MELO, M.S.C.; ROCHA, L.J.F.N.; BRUNHARO, C.A.C.G.; SILVA, D.C.P.; NICOLAI, M.; CHRISTOFFOLETI, P.J. Alternativas de controle químico do capim-amargoso resistente ao glyphosate, com herbicidas registrados para as culturas de milho e algodão. Revista Brasileira de Herbicidas, v. 16, n. 3, p.206-215. 2017. Disponível em: <https://dx.doi.org/10.7824/rbh.v16i3.556>. doi: 10.7824/rbh.v16i3.556

MELO, M.S.C.; SILVA, D.C.P.; ROSA, L.E.; NICOLAI, M.; CHRISTOFFOLETI, P.J. Herança genética da resistência de capim-amargoso ao glyphosate. Revista Brasileira de Herbicidas, v. 14, n. 4, p. 296-305. 2015. Disponível em: <http://dx.doi.org/10.7824/rbh.v14i4.443>. doi: 10.7824/rbh.v14i4.443

MENDONÇA, G.S.; MARTINS, C.C.; MARTINS, D.; COSTA, N.V. Ecophysiology of seed germination in Digitaria insularis ((L.) Fedde). Revista Ciência Agronômica, v. 45, n. 4, p. 823-832. 2014. Disponível em: <www.ccarevista.ufc.br>.

NETTO, A.G.; GOVEIA, Y.D.; CARVALHO, S.J.P. Monitoring the occurrence of glyphosate-resistant sourgrass biotypes in the south region of Minas Gerais, Brazil. 
Revista Brasileira de Herbicidas, v. 14, n. 1, p. 38-46. 2015. Disponível em: <http://dx.doi.org/10.7824/rbh.v14i1.400>. doi: 10.7824/rbh.v14i1.400

PEREIRA, G.R.; COSTA, N.V.; MORATELLI, G.; RODRIGUES-COSTA, A.C.P. Growth and development of Digitaria insularis byotypes susceptible and resistant to glyphosate. Planta Daninha, v. 35, e017160505. 2017. Disponível em: <http://dx.doi.org/10.1590/S0100-83582017350100025>. doi: 10.1590/S0100-83582 017350100025

PEREIRA, G.R.; ZOBIOLE, L.H.S.; ROSSI, C.V.S. Resposta no controle de capimamargoso à mistura de tanque de glyphosate e haloxifope com auxinas sintéticas. Revista Brasileira de Herbicidas, v. 17, n. 2, e606. 2018. Disponível em: <http://dx.doi.org/10.7824/rbh.v17i2.606>. doi: 10.7824/rbh.v17i2.606

PETTER, F.A.; SULZBACHER, A.M. ; SILVA, A.F.; FIORINI, I.V.A.; MORAIS, L.A.; PACHECO, L.P. Use of cover crops as a tool in the management strategy of sourgrass. Revista Brasileira de Herbicidas, v. 14, n. 3, p. 200-209. 2015. Disponível em: <http://dx.doi.org/10.7824/rbh.v14i3.432>. doi: 10.7824/rbh.v14i3.432

RODRIGUES, B.N.; ALMEIDA, F.S. Guia de herbicidas. 7. ed. Londrina: Ed. Autores, 2018. $764 \mathrm{p}$.

SILVA, F.A.S.; AZEVEDO, C.A.V. The assistat software version 7.7 and it's use in the analysis of experimental data. African Journal of Agricultural Research, v. 11, n.39, p. 3733-3740. 2016. Disponível em: <https://dx.doi.org/10.5897/AJAR2016.115 22>. doi: 10.5897/AJAR2016.11522

TROPALDI, L.; ARALDI, R.; BRITO, I.P.F.S.; SILVA, I.P.F.; CARBONARI, C.A.; VELINI, E.D. Herbicidas inibidores do fotossistema II em pré-emergência no controle de espécies de capim-colchão. Revista Brasileira de Herbicidas, v. 16, n. 1, p. 30 37. 2017. Disponível em: <http://dx.doi.org/10.7824/rbh.v16i1.528>. doi: 10.7824/rbh. v16i1.528

ZIMMERMANN, F.J.P. Estatística aplicada à pesquisa agrícola. Santo Antônio de Goiás-GO: Embrapa Arroz e Feijão, 2004. 402 p.

ZOBIOLE, L.H.S.; KRENCHINSKI, F.H. ; ALBRECHT, A.J.P.; PEREIRA, G.; LUCIO, F.R.; ROSSI, C.; RUBIN, R.S. Controle de capim-amargoso perenizado em pleno florescimento. Revista Brasileira de Herbiçidas, v. 15, n. 2, p. 157-164. 2016. Disponível em: <http://dx.doi.org/10.7824/rbh.v15i2.474>. doi: 10.7824/rbh.v15i2.474

ZOBIOLE, L.H.S.; KRENCHINSKI, F.H.; PEREIRA, G.R.; RAMPAZZO, P.E.; RUBIN, R.S.; LUCIO, F.R. Management programs to control Conyza spp. in pre-soybean 
sowing applications. Planta Daninha, v. 36, e018175883. 2018. Disponível em : <http://dx.doi.org/10.1590/S0100-83582018360100076>. doi: 10.1590/S0100-83582 018360100076 